\title{
TU/e EmonONEN

\section{Knowledge sharing behavior: the role of spatial design in buildings}

\section{Citation for published version (APA):}

Appel - Meulenbroek, H. A. J. A., de Vries, B., \& Weggeman, M. C. D. P. (2017). Knowledge sharing behavior: the role of spatial design in buildings. Environment and Behavior, 49(8), 874-903.

https://doi.org/10.1177/0013916516673405

DOI:

10.1177/0013916516673405

Document status and date:

Published: 01/10/2017

\section{Document Version:}

Accepted manuscript including changes made at the peer-review stage

\section{Please check the document version of this publication:}

- A submitted manuscript is the version of the article upon submission and before peer-review. There can be important differences between the submitted version and the official published version of record. People interested in the research are advised to contact the author for the final version of the publication, or visit the $\mathrm{DOI}$ to the publisher's website.

- The final author version and the galley proof are versions of the publication after peer review.

- The final published version features the final layout of the paper including the volume, issue and page numbers.

Link to publication

\section{General rights}

Copyright and moral rights for the publications made accessible in the public portal are retained by the authors and/or other copyright owners and it is a condition of accessing publications that users recognise and abide by the legal requirements associated with these rights.

- Users may download and print one copy of any publication from the public portal for the purpose of private study or research.

- You may not further distribute the material or use it for any profit-making activity or commercial gain

- You may freely distribute the URL identifying the publication in the public portal.

If the publication is distributed under the terms of Article 25fa of the Dutch Copyright Act, indicated by the "Taverne" license above, please follow below link for the End User Agreement:

www.tue.nl/taverne

Take down policy

If you believe that this document breaches copyright please contact us at:

openaccess@tue.nl

providing details and we will investigate your claim. 


\title{
Knowledge Sharing Behavior: The Role of Spatial Design in Buildings
}

\section{Rianne Appel-Meulenbroek', Bauke de Vries', and Mathieu Weggeman'}

\begin{abstract}
Knowledge sharing during unplanned face-to-face meetings between employees is indispensable for innovation-based organizations. Spatial design of office buildings has been proven to influence the number of meetings dyads have at work, but research on the behavior during such meetings remains scarce. This article analyzes how several spatial variables relate to employee behavior during such meetings (joint activities, location, intentionality, and issues addressed). A I-week diary of 138 employees from one research organization provided data on 918 knowledge-sharing meetings. Analysis of the building layout showed that behavior is particularly different at a very local level within the building. Chi-square tests showed that inter-visibility and proximity are most strongly associated with where knowledge was shared, while sharing a room and overhearing related significantly to how knowledge was shared.
\end{abstract}

\section{Keywords}

knowledge sharing, distances, employees, office design, behavior

'Eindhoven University of Technology, The Netherlands

\section{Corresponding Author:}

Rianne Appel-Meulenbroek, Chair of Real Estate Management \& Development, Eindhoven University of Technology, P.O. Box 5I3, VRT 8.30, 5600 MB Eindhoven, The Netherlands. Email: h.a.j.a.appel@tue.nl 
When innovation is a high priority, organizations should stimulate brief informal interactions between employees (Heerwagen, Kampschroer, Powell, \& Loftness, 2004). Wang and Wang (2012) showed that knowledge-sharing practices facilitate both innovation and firm performance. The knowledge shared during such interactions thus advances the innovation process (Allen \& Henn, 2007; Nenonen, 2005). Corporate real estate (CRE) managers can play an important role in stimulating interactions between employees and thus supporting organizational innovation (Toker \& Gray, 2008; Wineman, Kabo, \& Davis, 2009). The same is true for the planners, designers, and office building managers who provide services to them. But to be able to do so, all these need to know exactly how the building and its workspaces relate to behavior that supports innovation like knowledge sharing (KS).

Spatial design has been shown to affect interactions between employees (Coradi, Heinzen, \& Boutellier, 2015; Kabo, Hwang, Levenstein, \& OwenSmith, 2015). But innovation and knowledge management studies have typically measured aspects of spatial design with the distance between buildings on a campus or whether employees work in the same building (e.g., Kahn, 1996; Song, Berends, Van der Bij, \& Weggeman, 2007). Work environment academics have measured spatial design in much more detail, but not often within the context of KS. Only recently, the relationship between spatial design and KS has gained more interest and in both fields more detailed studies have been published (e.g., Coradi et al., 2015; Kabo et al., 2015; Wineman, Hwang, Kabo, Owen-Smith, \& Davis, 2014). Such studies have shown, for example, that visibility leads to more cross-functional interactions (Coradi et al., 2015) and shorter walking distances to more joint funding applications (Kabo et al., 2015). But this relationship needs to be studied further if we are to understand how to design workspaces inside a building to stimulate specific behavior.

So far, the focus remains largely on effects of spatial layout variables on frequency of interactions (e.g., Sailer \& Penn, 2009; Spiliopoulou \& Penn, 1999), but not on the content of these interactions. Such meetings could just as well be about how somebody likes his or her coffee. This is hardly proof that relevant knowledge was shared. Only a few studies have looked at relationships between spatial design and output variables that go beyond measuring mere frequency of interactions, like collaboration, different types of interactions, or awareness of others (e.g., Covi, Olson, \& Rocco, 1998; Hua et al., 2011; Peponis et al., 2007). However, often such studies are a literature review or ask employees how they perceived the support. It is necessary to measure more precisely if and how KS took place, between whom, and whether it was affected by specific quantifiable variables of their spatial relationship. 
As Kabo et al. (2015) pointed out, the dyad is "the most elemental level of analysis for understanding networks based on information sharing, collaboration, or teamwork" (p. 58). They also mention that dyads have received very little attention with regard to the effect of how they are situated in space on their joint behavior. Existing studies of dyads have shown, for example, that walking distances of more than 24 to $30 \mathrm{~m}$ discourage chance meetings (Allen, 1977) and that overlap of the zone of the building that employees move through increases joint applications for grants by academics (Kabo et al., 2015). These studies use sophisticated techniques to measure the spatial relationship of a dyad in AutoCAD drawings. Although some studies have addressed the link from spatial relationships to KS outcomes, few if any have addressed the intermediate (to outcomes) links between spatial relationships and detailed KS behavior. Their spatial measures focus on meeting the other when moving around in the building, but neglect how the mutual position of workspaces creates awareness of the other during the rest of the day (e.g., seeing or overhearing the other from behind their desk) and how this might relate to how and where dyads are able to share knowledge.

The purpose of the present study was to clarify how several detailed local and more global layout metrics are related to more detailed behavior during meetings (intentionality, the activities performed together, location of the meeting, and issues addressed). Data about KS behavior were collected through interaction-diaries of 138 employees from one large research-based organization. Data on the spatial relationship were collected with spatial network analysis of layout drawings. The significance of the differences between dyads was tested with $\chi^{2}$ tests.

In the next section, we review the literature on KS behavior and use it to formulate hypotheses and explore possible relationships between KS and spatial design aspects. Next, the "Method" section describes how the data were gathered and which statistical techniques were used to test the hypotheses. After describing the data, the results are discussed in light of the hypotheses, followed by a discussion and future research directions.

\section{KS Behavior}

The two main streams within epistemology diverge on how knowledge can be transferred during meetings. Objectivists often treat knowledge as an entity that can be codified and then transferred easily. The practice-based perspective, which emerged over the past decade (Berends, Garud, Debackere, \& Weggeman, 2011), stresses the embeddedness of knowledge in human activity. Following Polanyi (1966), many academics distinguish between explicit knowledge (information) and tacit knowledge (derived from 
experience and including beliefs and values; Nonaka \& Takeuchi, 1995). The practice-based perspective supports that all knowledge is tacit to some extent. These knowledge components differ in how they affect innovation. Wang and Wang (2012) showed that explicit KS had more significant effects on innovation speed and tacit KS on innovation quality.

Tacit knowledge is shared best when supported by motions and gestures and thus through face-to-face meetings (Coradi et al., 2015). Studies often assume that the more meetings take place, the more knowledge is shared and thus KS output is primarily measured with the number of interactions (e.g., Toker \& Gray, 2008). However, mere quantitative analysis of face-to-face meetings is insufficient as this does not take into consideration why and how knowledge is shared, or even if knowledge is shared at all. As Hua, Loftness, Heerwagen, and Powell (2011) stated, "For collaboration to succeed, rich interactions are important" (p. 808). To use the physical work environment to support KS behavior, more detailed behavioral measurements correlating to building design are required.

Berends (2003) examined the KS behavior of industrial researchers in detail (without relating this to the physical work environment) and identified five categories of KS moves during which knowledge is shared in a certain way:

- Giving descriptions (e.g., reporting about others or describing one's own activities, knowledge, problems, findings, etc.);

- Performing actions (e.g., demonstrating, on the spot calculating, expressing observation);

- Asking questions;

- Making proposals (e.g., hypothesizing, suggesting solutions, warning, referring to literature);

- Evaluating (e.g., giving arguments, agreeing, rejecting, concluding).

These five categories of moves seem very suitable to use as metrics for underlying research. All are commonly used in daily activities and their definition should therefore be clear to all respondents. The specific moves can be used as operational definitions/examples for respondents. For more insight into what issues are addressed during meetings, it is also interesting to look at whether the knowledge shared concerned a shared or a single problem or perhaps was not problem oriented at all (Berends, 2005).

Besides the KS moves and issues addressed, the intentionality of a meeting is relevant too. The majority of KS meetings within organizations are spontaneous face-to-face encounters (Toker \& Gray, 2008). Planned meetings are less likely to be a result of the physical work environment (Peponis 
et al., 2007; Toker \& Gray, 2008) as are unscheduled conversations. Brown (2008) distinguished between "Intentional unscheduled visits" (the initiator of the conversation walked up to someone) and conversations "Initiated after coincidental visual contact" (partners happened to see each other and started talking).

To support unplanned meetings, it is also important to know where these take place inside the building. The "serendipitous communication model" coined by Peponis et al. (2007) suggests that spaces and facilities supplementary to a personal workspace (coffee machines, hallways, drop down seats, etc.) are particularly important for increasing KS among employees. Many modern office designers are firm believers in this model and create places for the specific purpose of stimulating these incidental chats. Even employees are convinced that the distance between their workspace and such places is more important for spatial support of their collaboration than individual workspace aspects (Hua et al., 2011). However, it remains unclear whether the use of these types of spaces actually influences KS behavior. Studies of buildings for researchers (e.g., Peponis et al., 2007; Serrato \& Wineman, 1999) showed that talking between employees primarily takes place near the workspace, instead of in hallways. Boutellier, Ullman, Schreiber, and Nael (2008) even found that office employees rarely used soft sitting areas specifically intended for communication. Therefore, the "flow model" coined by Peponis et al. (2007) seems more relevant, as it argues that people who rely on intercommunication must be located near each other (also known as propinquity theory). In the current study, the flow model formed the basis for the hypotheses formulated in the next section.

\section{Hypotheses for Placement of Dyads in a Building}

Often, studies that try to measure the effect of the physical work environment on organizational outcomes use a pre-post questionnaire or observation study to look at relocations changing which dyads are co-located in the same building (e.g., Blakstad, Hatling, \& Bygdås, 2009; Kahn \& McDonough, 1997; Sailer, Budgen, Lonsdale, Turner, \& Penn, 2007). Although such longitudinal studies are interesting, they are also very context sensitive. The same employees have a certain number of meetings before and after being collocated with different colleagues. Organizational changes that are made concurrent with any regrouping decision make it hard to show a relationship with the physical work environment on its own (Bell \& Anderson, 1998; Coradi et al., 2015). Also, the layout is not always quantified in measurable items (e.g., Hoegl \& Proserpio, 2004), so a total work environment is judged without understanding how the change in behavior of specific employees was influenced by their 
workspaces. Through a content analysis of work environment literature, five different variables were identified to study the placement of dyads in a building in more detail and form hypotheses with regard to their KS behavior. These variables are collocation (sharing a room), inter-visibility, overhearing, proximity (walking distance $<30 \mathrm{~m}$ ), and having their workspaces on the same floor. As per Rashid et al. (2005), the first three represent a local level (co-presence), whereas the other two represent a global level (position in the building).

\section{Co-Presence}

A possible relationship between co-presence and KS can be viewed in the light of the theory of cognitive apprenticeship, developed by Collins, Brown, and Newman (1989), which is typical for the practice-based perspective. Studies of the brain have shown that collocated people imitate each other (Goleman \& Boyatzis, 2008), which is an important part of organizational learning (Covi et al., 1998). So, sharing a (project) room can be beneficial for collaboration (Blakstad et al., 2009; Heerwagen et al., 2004). It might make it easier to ask questions, perform actions together, and go through the repetitive team actions of evaluation and making suggestions. This brings us to the following hypothesis:

Hypothesis 1 (H1): Dyads sharing a room (collocation) show different KS behavior than the other dyads.

People who can see each other at their workstations, can collaborate, share tasks and ideas more easily, and provide assistance (Jassawalla \& Sashittal, 1998). They are more aware of other people's need for help (Nonaka \& Konno, 1998; Sailer et al., 2007). This awareness might increase KS activities such as making suggestions, expressing observations, or referring to relevant knowledge sources. More visual contact also contributes to fewer distractions, by changing the timing of communication (Becker \& Sims, 2001). These studies suggest that inter-visibility might change the behavior of a dyad.

Hypothesis 2 (H2): Dyads that can see each other's workspaces (intervisibility) show different KS behavior than the other dyads.

Open workspaces enhance face-to-face interaction through both seeing and overhearing (Rashid, Kampschroer, Wineman, \& Zimring, 2006; Sailer et al., 2007). With the current large open office concepts, sharing a room or 
seeing the other's workspace does not necessarily mean that dyads are also within hearing distance. So this may be another relevant measure.

Hypothesis 3 (H3): Dyads sitting within hearing distance (overhearing) show different KS behavior than the other dyads.

\section{Position in the Building}

Not every employee can be within inter-visibility and hearing distance of all other employees in an organization. But as others (Allen, 1977; Wineman et al., 2009) have shown, people working in different rooms but within proximity of each other still meet more often than people whose rooms are further apart. Dyads with a lower walking distance might interact more, if they bump into each other when moving around in the vicinity of their workspace (going to a printer, restroom, etc.). During these chance encounters, KS activities such as giving descriptions and reporting about others could take place. The "forced" meetings that take place break down boundaries and force people from different communities to understand each other better (Ward \& Holtham, 2000). Kahn and McDonough (1997) also found higher levels of achieving goals together and a shared vision as positive results. These studies suggest that walking distance might change the behavior of a dyad.

Hypothesis 4 (H4): Dyads with a lower walking distance between their workspaces (proximity) show different KS behavior than the other dyads.

People working on different floors of the same building meet less frequently than those working on the same floor (Spiliopoulou \& Penn, 1999). But Spiliopoulou and Penn also state that this effect is a lot smaller than the effect of working in close vicinity versus at larger distance on the same floor. The effect becomes even smaller when the floors are bigger (Grajewski, 1992). Allen and Henn (2007) showed that beyond one's own floor, the interaction declines dramatically and is almost equal to interaction with people from other buildings or locations. Only a strong functional relationship makes people interact between floors.

Hypothesis 5 (H5): Dyads with a workspace on the same floor show different KS behavior than the other dyads.

Now that the hypotheses are clear, it is important to examine how to quantify space in such a way that statistical testing is possible. 


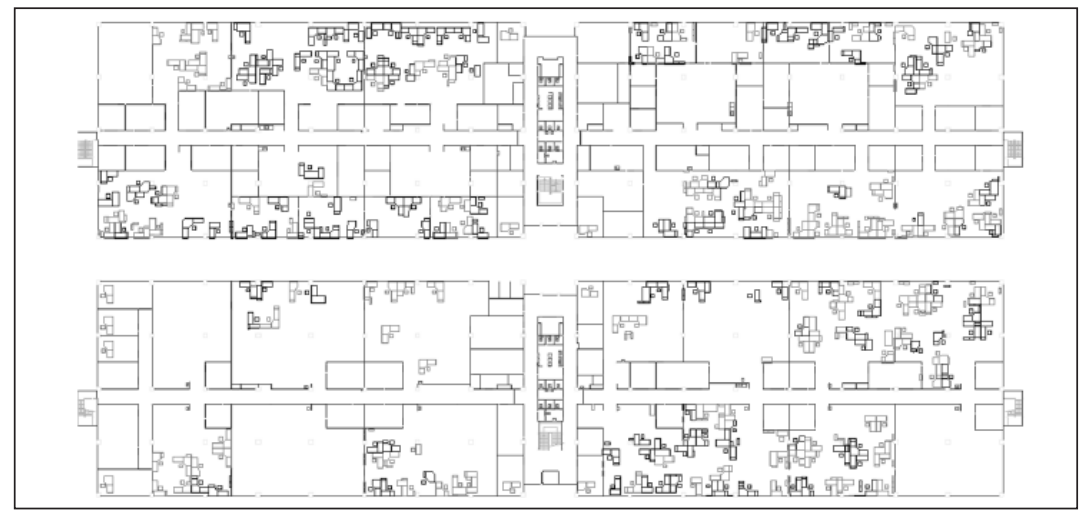

Figure I. Case building layout ground and first floor (Appel-Meulenbroek, 20I0).

\section{Method}

To test the hypotheses in this study, detailed spatial data are necessary on employee dyads within a building and on their behavior.

\section{Participants}

The study site is one of the world's leading providers of document management and printing for professionals. One building was chosen because the research and development employees of this organization in the Netherlands work there. It has two floors (Figure 1) with both large and small rooms, ranging from single-person rooms to open areas with up to 29 workspaces. Small lab areas without daylight were concentrated around the corridors, and a few large lab areas with less specific climate conditions were located in areas similar to the offices. This building accommodated 269 employees at that time. The 138 research and development employees $(51 \%$ of the building population) who agreed to keep the diary during 1 week made 9,453 potential dyads for KS meetings. Ninety-six percent of the sample was male, aged between 19 and 60 years $(M=41, S D=010)$ and was representative of the parent organization. They were spread out regularly over the entire building and the rooms. They also represented at least one third of each department in the organization and of each project that the organization was working on at that time. The online appendix to this article provides the number of employees working in the rooms that had participants. In 12, rooms there were fewer than 10 workspaces and in nine rooms there were 12 or more workspaces. Each of the managers had an enclosed workspace or room, but only one of the 
managers participated. Therefore most single-person rooms were not included in the study, and only $28 \%$ of the participants worked in rooms with fewer than 10 workspaces.

\section{Measures: Spatial Data}

It is relatively easy to gather spatial data for H1 (collocation), H2 (intervisibility), and $\mathrm{H} 5$ (same floor). H3 (overhearing) and H4 (proximity) deal with distances that need to be measured between each dyad. This is a laborious process when not automated, as over a hundred employees creates the possibility for thousands of possible different dyads for which these distances need to be gathered. In the past decade, spatial network analysis techniques (some of which are called space syntax) have been applied to many different spatial urban environments and types of buildings to measure distances (and other quantitative characteristics of buildings). The distance "as the crow flies" can be used as an approximation in large settings (e.g., cities), but is unsuitable to study smaller spatial systems like a building (Sailer $\&$ McCulloh, 2012). Therefore, many building studies have quantified the office layout in a topological way to approximate distance (e.g., Peponis et al., 2007; Rashid et al., 2006; Toker \& Gray, 2008; Wineman \& Adhya, 2007; Wineman et al., 2009). But although Kabo et al. (2015) found that in office buildings the walking distance is highly correlated with the topological "turn distance," it seems more accurate in a building with a mixture of large open areas and cellular offices to more closely approximate the actual walking distance. Therefore, following Hua, Loftness, Kraut, and Powell (2010), the distances in this article were computed using "graph metric" geometry, "which is the shortest distance between two points along an orthogonal path that passes inside the shape (floor plate)" (Hua et al., 2010, p. 433). Compared with the taxicab distance and "as the crow flies" distance, this is said to be closest to approximating circulation routes in buildings (Hua et al., 2010; Shpuza, 2006).

Such visual graph analysis (VGA) is based on isovists, which are defined by Benedikt (1979) as "the set of all points visible from a given vantage point in space and with respect to an environment" (p. 47). Isovists have been shown to capture how people experience their environment (e.g., spaciousness, complexity; Franz \& Wiener, 2008). Turner, Doxa, O'Sullivan, and Penn (2001) used isovists placed on a regular grid, to derive a visibility graph, which they defined as a "graph of mutually visible locations in a spatial layout" (Turner et al., 2001, p. 104). Each grid point is called a node and if it is connected to another node a line (also called edge) can be drawn between those two nodes. Just as isovists describe single observation points, visibility 
graphs describe the layout of the floor as a whole from the viewpoint of exposure (Franz, Von der Heyde, \& Bülthoff, 2005). Many measures of visibility graphs have been used, but for this article we only used the graph to move through the layout like people are able to do in reality (so avoiding walls and other structural obstacles). Each node can be seen as a potential place for a person. Because all nodes that can see each other (and thus one can walk from this node straight to the other) are connected by lines when the visual graph is created, the VGA grid can then be used to approximate metric walking distances. This is a close approximation of the actual metric distance because it measures the distance between the center of the grid squares, but will move around obstacles in the drawing.

A valid distance for overhearing was necessary to test H3. Generally, the speech transmission index (STI) developed by Houtgast and Steeneken at TNO Netherlands (Steeneken, 1998) is used to measure hearing distance. The STI estimates the intelligibility of sounds. It varies between 0 and 1 , and has to be 0.6 or higher for good or excellent sound intelligibility (Steeneken, 1998). The "paradox of verbal communication" in research buildings is that while on one hand privacy is needed for concentration, on the other hand, speech intelligibility helps collaboration. Most acoustics studies focus on speech privacy, while for this study the opposite is more relevant. Studies focusing on intelligibility mostly look at warning sounds (e.g., fire alarm). Besides distance between sound and receiver, other relevant aspects to determine intelligibility differ per office and conversation, like the background noise, speech level, and room acoustics (Wenmaekers, Van Hout, Hak, \& Van Luxemburg, 2009). So, a specific optimal distance is not available. But studies of the optimal distance to achieve an STI of at least 0.6 (Keränen, Virjonen, \& Hongisto, 2008; Wenmaekers et al., 2009) have identified a value for hearing distance between 5 and $10 \mathrm{~m}$. Within this range, dyads can probably overhear each other when sitting at their workspace. The actual split for this variable within this range was therefore determined based on the data. For $\mathrm{H} 4$, the dyads were split into two groups at $30 \mathrm{~m}$. This choice was based on findings from early and recent literature indicating this distance as a cutoff point for higher chances of meeting (e.g., Allen, 1977; Allen \& Fustfeld, 1975; Sailer \& Penn, 2009).

\section{Measures: Behavioral Data}

Many different methods exist to gather data on KS behavior. Studies on work environments generally study employees in their natural settings as they need to adjust to their surroundings before any influence becomes visible. As Tan (2003) demonstrated, a diary outperforms a questionnaire in the validity of 
the data it provides on trips and activities undertaken. It cuts the time lag between the event happening and being recorded (Bolger, Davis, \& Rafaeli, 2003). As many unplanned KS meetings are short, they are easily forgotten when filling in a questionnaire at some point of the day. Logging meetings in a diary throughout the day should capture more of these meetings. In addition, a diary can ask specific questions on each specific meeting. In this study, a diary was kept for a whole work week to capture the different types of meetings that might occur on different days of the week (like start-up meetings on Monday mornings). To minimize behavioral changes (Hawthorne effect), it was explained during the personal recruitment of participants and distribution of the diaries that the study focused on improving the building layout and not the behavior itself. We also explained that results would be kept confidential and individual behavior would not be reported to management.

Greenberg et al. (2005) stated three additional problems with diaries that should be considered, namely, memory (when is it completed), authorship (who filled it out), and mortality (how long a respondent was diligent). The diary created for this study was a printed booklet that was positioned on the desks of the participants, so that its visibility would prompt them to fill in their meetings during the day and not at the end of the day. To further deal with memory issues, the first author walked around in the building during the week that the diaries were kept, as a reminder to fill out the diary. It was regularly observed that participants were writing in their diary, reducing possible authorship problems. As participation was optional and the respondents were researchers themselves, it seemed very unlikely that they would delegate diary entry to someone else. From Tuesday through Thursday, we see no signs of data mortality as there is no decline in the number of meetings in the logbooks (see Table 2 in the online appendix). The percentage of participants that was present at work each day appeared to explain the higher number of meetings on Monday. However, the relatively low number of meetings on Friday compared with Tuesday might be due to mortality.

The first page of the diary asked for days present at work, name, and where the workspace is located. The rest of the diary contained identical pages to fill in data on two meetings per page. Only unplanned face-to-face meetings in which work-related issues came up had to be logged. For each meeting, respondents logged date, start time, duration, and conversation partners. This information was used to see if employees who met both filled in the same conversations. This made it possible to complete the database in the event where someone forgot to fill in a meeting while their counterpart did. Next, the diary asked for the KS behavior variables to test the hypotheses. To expedite time and effort, all questions were in the form of multiple choice. The initial questions regarded the five types of KS behavior, termed moves by 
Berends (2003) as discussed earlier (descriptions, actions, questions, proposals, evaluations). Reference was made to the last page of the logbook that contained the specific moves of each category as examples to further clarify the meaning of each possible answer category. Next, the location within the building had to be entered where the meeting took place (whose workspace, which meeting area or project room, at a coffee machine, or in the hallway). Participants also had to fill in intentionality (choosing between intentional unscheduled visit and initiated after coincidental visual contact) and issues addressed (shared problem, problem of the respondent, problem of the other, or not problem oriented). To identify whether meetings were intentional or initiated on the spot, the diary also asked who initiated the meeting (the respondent or the other) as only the initiator knows whether the meeting was an intentional visit or not. Unplanned meetings with more than two people do not take place very often, but in these cases, the meeting was added to the total for each possible dyad among the participants in that meeting.

\section{Procedure}

In a pilot, the diary was tested for 1 week in a university building with 40 university employees, located on the same floor of one building, representing $59 \%$ of the population of this floor. In this week, they logged 251 unique meetings. Responses of the meeting participants on whether each KS move took place corresponded for at least $68 \%$ of the meetings. This suggested that the terms were clear enough for use in the diary, but that participants did not always agree about which activities they performed. It was decided to include the logbooks of both participants in the analyses if this would also be visible in the data from the study site. As the number of activities that participants disagreed on significantly correlated with the duration of the meeting, $r$ (232) $=.328$, it was likely that part of the deviation between answers was due to memory issues when the meeting lasted longer. Because the activities were common words and we gave examples in the back of diary, it seemed more likely that this activity also took place and that one of them forgot to tick it, than that they disagreed on the meaning of the words used to describe the activity. Another, more general, check was done by comparing the duration of meetings in both diaries of each dyad in the pilot. The difference between the duration filled in was a mere 5 min or less for $89 \%$ of the meetings. This suggested that duration interpretation is something that people could do adequately. The test subjects all indicated that they had no major problems filling in the diary. Therefore, based on the results of the pilot, the diary format was not changed for the actual study site. 
As the final data set again showed that approximately $40 \%$ of the meeting partners did not fully agree on the KS activities that took place, it was decided to indeed include the logbooks of both participants in the analyses. This doubled the number of cases in the database. In case meeting partners agreed, both lines in the database are identical, but if they did not, the lines contained their individual opinion on the meeting. To check for the influence of age (12 participants did not want to disclose their age), we examined the correlation with the different logbook variables. The only significant correlations that we observed were that older employees used fewer descriptions, $r(126)=-.275$, and proposals, $r(126)=-.250$, initiated fewer meetings after visual contact, $r(126)=-.244$, and had fewer meetings that were not problem oriented, $r(126)=-.227$. As all these correlations were low, age was not considered for further analyses. With the lack of variance in gender, this was not tested further. Although Criscuolo, Salter, and Ter Wal (2010) already showed that short distances in the office are not highly correlated with organizational proximity, we checked for our study data as well. The spatial location of the dyads was significantly correlated with the organizational structure (being on the same team, different team in the same department, different department), but the correlations were low. The highest correlations were seen for the dyads from the same team, which positively correlated with inter-visibility, $r(9,453)=.229$, and negatively with being located on different floors, $r(9,453)$ $=-.224$. Therefore, organizational structure was also not considered to be an important confounder.

At the initial phase of the larger research project that this study was part of, the software program Depthmap (Version 7.12) developed by Turner (2001) was chosen to derive spatial data from the AutoCAD drawings because it could generate multiple and diverse measurements that were needed for the different phases of the entire research project. ${ }^{1}$ In the latest phase of the project (the current article looking at dyads), the use of Depthmap was maintained because it was able to generate the necessary graph metric distances as well (although this is not the core goal of this space syntax-based software program). To generate the graph metric distances between each dyad, the building layout was covered with a dense grid of $0.50 \times 0.50 \mathrm{~m}$ to obtain an accurate approximation of circulation routes. The distance of $0.50 \mathrm{~m}$ was justified by Franz and Wiener (2008), as it is between the average human step length $(0.6 \mathrm{~m})$ and body width $(0.45 \mathrm{~m})$. Each square was assigned a reference number, which was used to identify the workspace of participating employees during the analyses. The floors were connected in Depthmap at the three staircases at each end and in the middle of the building, to be able to calculate walking distances between floors as well. Depthmap cannot deal 
Table I. Correlation Between Layout Variables.

\begin{tabular}{|c|c|c|c|c|c|}
\hline $\begin{array}{l}\text { Spearman's rho } \\
\text { correlation }\end{array}$ & $\begin{array}{c}\text { Collocated } \\
n=9,453\end{array}$ & $\begin{array}{c}\text { Inter-visibility } \\
n=9,453\end{array}$ & $\begin{array}{c}\text { Overhearing } \\
n=570\end{array}$ & $\begin{array}{l}\text { Proximity } \\
n=8,883\end{array}$ & $\begin{array}{c}\text { Same floor } \\
n=9,453\end{array}$ \\
\hline Collocated & I & $.953 * *$ & & & $.242 * *$ \\
\hline Inter-visibility & & I & $-.259 * *$ & & $.230 * *$ \\
\hline Overhearing & & & 1 & & \\
\hline Proximity & & & & I & $-.368 * *$ \\
\hline Same floor & & & & & I \\
\hline
\end{tabular}

**Correlation is significant at the .01 level, two-tailed.

with the inter-floor distance (which was $2.70 \mathrm{~m}$ ), so the distance crossed while changing floors is ignored (like being in an elevator).

Turner et al. (2001) distinguished between a visibility and permeability graph (= visibility graph at floor level, to include furniture and other obstacles). In Depthmap, each layer within the AutoCad drawing can be turned on/ off prior to running an analysis. To study overhearing, a visibility graph was used to calculate "metric straight line distance" within rooms. For proximity, a permeability graph was used to calculate the "metric shortest path distance," so moving around obstacles in the layout. As Depthmap does not work with dyads, an individual analysis was done for each person, generating his or her distances to each colleague in the building separately. This involves selecting the grid square of a person's workspace in the layout in Depthmap and then letting the program generate the distance to each other grid square inside the building layout. From this individual distances table, the distances to grid squares that represented workspaces of colleagues were copied into SPSS for each dyad that this employee could form with other participants. This was repeated for each participant until the distances between all possible dyads were obtained for the KS behavior analyses. Probes of actual walking distances in the AutoCAD drawings showed that the obtained graph metric distances were accurate approximations.

Spearman's correlation was used to check correlation between the spatial variables (Table 1) because the distance variables did not have a normal distribution. All variables showed significant correlations with each other, but not all were strong. In this case, collocation and inter-visibility had a very high correlation, $r(9,453)=.953$. Therefore, $\mathrm{H} 2$ on seeing each other's workspace (inter-visibility) was tested only for the dyads sharing a room, as for them it did not correlate much with overhearing, $r(570)=-.259$, and thus was still an interesting additional variable. Overhearing is only relevant within a room, so this was also tested only for these 570 dyads. Overhearing and 
Table 2. Number of KS Meetings Versus Distance (for Dyads With $>0 \mathrm{KS}$ Meetings).

\begin{tabular}{lccccr}
\hline & M & Minimum & Maximum & SD & Total N \\
\hline Within hearing distance & 4.0 & $\mathrm{I}$ & 17 & 3.6 & 154 \\
Inter-visibility & 3.6 & $\mathrm{I}$ & 17 & 3.3 & 214 \\
Collocated, not visible & 2.8 & $\mathrm{I}$ & 6 & 1.8 & 8 \\
Same floor, different rooms & 1.9 & $\mathrm{I}$ & 12 & 1.6 & 136 \\
Different floors & 1.1 & $\mathrm{I}$ & 2 & 0.4 & 14 \\
\hline
\end{tabular}

Note. $\mathrm{KS}=$ knowledge sharing.

proximity for collocated dyads were highly correlated, $r(570)=.998$, because there are very few partitions that one has to walk around. Therefore, the hypothesis on proximity was only tested for dyads not sharing a room $(N=8,883)$, thus removing correlation with the co-presence measures and reducing issues of spatial auto-correlation. As can be expected, proximity also correlated with working on the same floor or not, $r(8,883)=-.368$, and sharing a room, $r(8,883)=.242$. However, the correlations were small enough to still test $\mathrm{H} 1, \mathrm{H} 4$, and $\mathrm{H} 5$ with these specific variables.

As the spatial variables are dichotomous and the behavioral variables contain multiple response categories, the hypotheses were tested with $\chi^{2}$ tests. To compare the relative effect size of the different spatial variables, this is calculated with Cramer's $V$ statistic. Applying Cohen's rule of thumb to indicate whether effect size is small (.10), medium (.30), or large (.50) is the most popular way to interpret effect size (Thompson, 2008).

For each dyad of participants, the number of KS meetings between them was counted to confirm the relationship between physical distance and the number of KS meetings, before testing the hypotheses on the behavior during these meetings. This sum included meetings as indicated by either one or both of the dyad partners, but duplicates were removed. Table 2 shows a clear trend of a decrease in meetings with an increase in distance for dyads that did share knowledge that week. This trend was also visible when creating this table for all dyads, with the mean number of meetings dropping to zero when dyads worked on different floors. So the data follow the results of previous studies. As frequency of meetings was not the aim of this article, this trend was not analyzed further.

\section{Results}

Obviously, not all dyads share a room (6\%). Of the collocated dyads in this case, $91 \%$ could see each other (inter-visibility). The straight line distance 


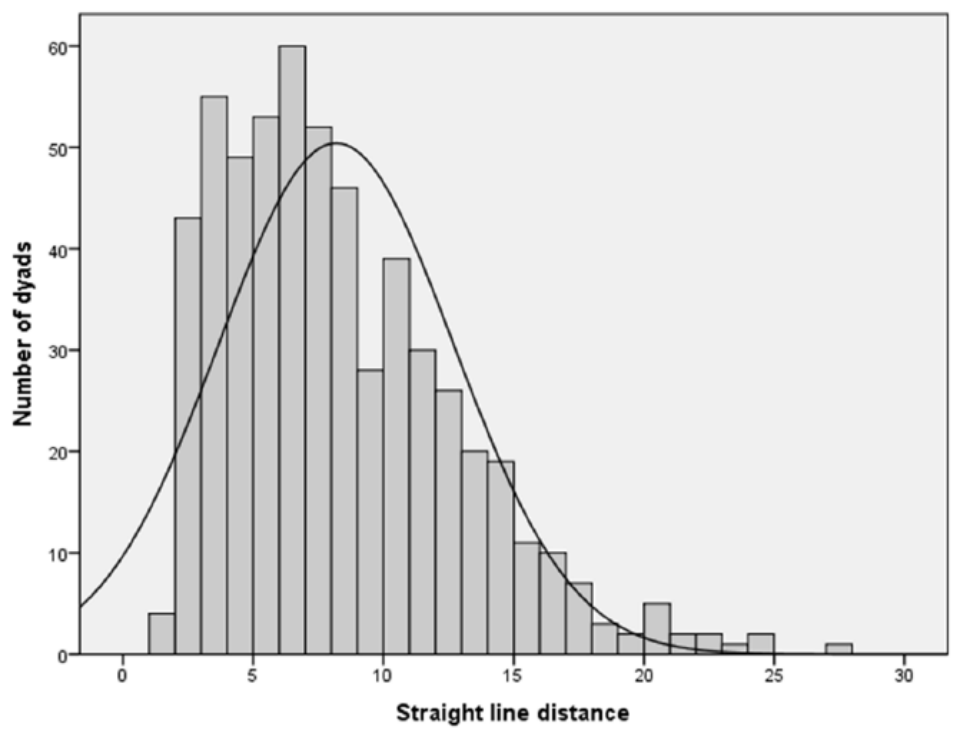

Figure 2. Straight line distances between dyads sharing a room.

between all the dyads in the same room is visible in Figure 2. To form two groups that can be compared in a similar way as the other dichotomous variables, the hearing distance was cut off at the median. As this was $7 \mathrm{~m}$, this seemed a valid split between overhearing and not, considering the STI discussed before. The walking distance between dyads in the building varied from $1.1 \mathrm{~m}$ up to $148 \mathrm{~m}(M=61, S D=029$; Figure 3$)$, with $11 \%$ of the dyads within proximity $(30 \mathrm{~m})$. The dichotomous measure "being on the same floor" was about evenly distributed ( $48 \%$ of the dyads worked on the same floor and $52 \%$ did not).

During $73 \%$ of the meetings, only one KS activity took place. Often knowledge was shared by asking and answering questions (56\%), while the other four KS activities only took place during approximately $20 \%$ of the meetings. Especially in the event that more than one activity occurred during a meeting, a proposal was often combined with questions (true of $43 \%$ of the proposals). But also, the other three activities were often combined with questions during a meeting: $36 \%$ of the actions, $32 \%$ of the descriptions, and $26 \%$ of the evaluations. So although questions can be the only KS activity during a meeting, they are also used often in combination with other KS activities. 


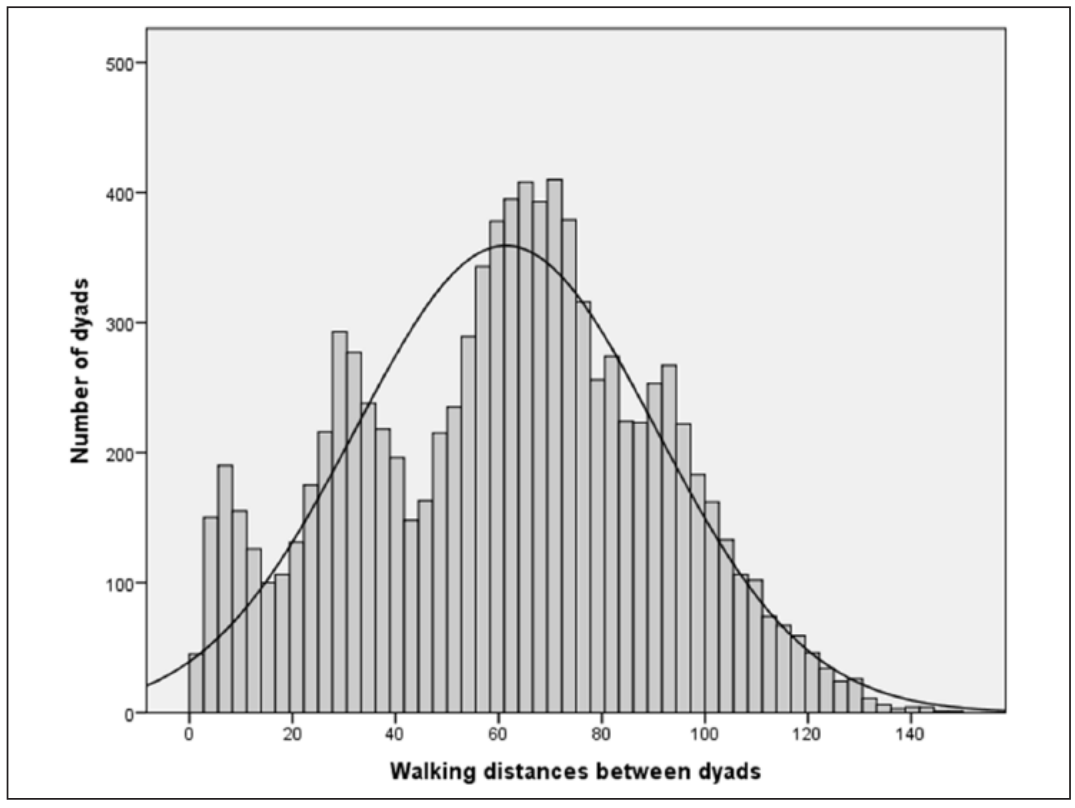

Figure 3. Walking distances between dyads.

On average, participants spent 45 min of their day involved in unplanned meetings (with a minimum of $1 \mathrm{~min} /$ day and a maximum of $6 \mathrm{hr}+38 \mathrm{~min} /$ day). Most KS took place during very short meetings of less than 15 min and $78 \%$ of the meetings took place at a workspace. Looking at the intentionality, $72 \%$ of the meetings took place because somebody intentionally walked over to meet the other person, or they had their workspaces so close that they could talk with each other from behind their desks. Often meetings regarded a shared problem (45\%), but there were also not problem-oriented meetings $(11 \%)$, so this is not a requisite for sharing knowledge.

As there were 855 meetings with two participants, 55 meetings with three participants, and eight meetings with four participants, the final data set contained $(855 \times 2+55 \times 3+8 \times 4=) 1,907$ cases. The behavior during the meetings showed several significant differences between dyads based on their spatial relationships (see Table 3 for frequencies of observed behavior). The way knowledge was shared differed significantly between collocated dyads and dyads from separate rooms although the effect size was small, $\chi^{2}(4$, $N=2,578)=11.12, p=.03$, Cramer's $V=.07$. Dyads from different rooms were more likely to use questions and used fewer proposals/evaluations. 
Table 3. Observed Frequencies for KS Behavior During the Meetings.

\begin{tabular}{|c|c|c|c|c|c|c|c|c|c|c|}
\hline & \multicolumn{2}{|c|}{ Collocated } & \multicolumn{2}{|c|}{$\begin{array}{c}\text { Inter- } \\
\text { visibility }\end{array}$} & \multicolumn{2}{|c|}{ Overhearing } & \multicolumn{2}{|c|}{ Proximity } & \multicolumn{2}{|c|}{ Same floor } \\
\hline & Yes & No & Yes & No & $<7 m$ & $>7 \mathrm{~m}$ & $<30 \mathrm{~m}$ & $>30 \mathrm{~m}$ & Yes & No \\
\hline Descriptions & 324 & 99 & 316 & 8 & 285 & 39 & 58 & 41 & 417 & 6 \\
\hline Actions & 231 & 90 & 225 & 6 & 196 & 35 & 61 & 29 & 315 & 6 \\
\hline Questions & 761 & 306 & 748 & 13 & $56 I$ & 200 & 191 & 115 & 1,053 & 14 \\
\hline Proposals & 283 & 89 & 273 & 10 & 228 & 55 & 55 & 34 & 366 & 6 \\
\hline Evaluations & 310 & 85 & 302 & 8 & 256 & 54 & 33 & 52 & 385 & 10 \\
\hline Workspace & I,I 29 & 357 & $\mathrm{I}, 107$ & 22 & 885 & 244 & 239 & I I 8 & $\mathrm{I}, 470$ & 16 \\
\hline Meet area & 21 & I & 21 & 0 & 21 & 0 & I & 0 & 22 & 0 \\
\hline Project area & 193 & 81 & 189 & 4 & 152 & 41 & 25 & 56 & 265 & 9 \\
\hline Coffee machine & 48 & 33 & 37 & II & 28 & 20 & 19 & 14 & 81 & 0 \\
\hline Hallway & 21 & 18 & 21 & 0 & 17 & 4 & 6 & 12 & 33 & 6 \\
\hline $\begin{array}{l}\text { Intentional } \\
\text { unscheduled } \\
\text { visit }\end{array}$ & 1,016 & 342 & 993 & 23 & 784 & 232 & 218 & 124 & 1,342 & 16 \\
\hline $\begin{array}{l}\text { Initiated after } \\
\text { coincidental } \\
\text { visual contact }\end{array}$ & 390 & 143 & 376 & 14 & 315 & 75 & 67 & 76 & 518 & 15 \\
\hline $\begin{array}{l}\text { Problem of one } \\
\text { person }\end{array}$ & 580 & $28 I$ & 565 & 15 & 450 & 130 & 179 & 102 & 843 & 18 \\
\hline $\begin{array}{l}\text { Problem of both } \\
\text { persons }\end{array}$ & 685 & 143 & 667 & 18 & 536 & 149 & 78 & 65 & 821 & 7 \\
\hline $\begin{array}{l}\text { Not problem } \\
\text { oriented }\end{array}$ & 147 & 63 & 143 & 4 & 116 & 31 & 30 & 33 & 204 & 6 \\
\hline
\end{tabular}

Note. Only bold printed comparisons showed significant differences in the $\chi^{2}$ tests.

$\mathrm{KS}=$ knowledge sharing.

People from different rooms also shared knowledge relatively more often in the hallway, at the coffee machine, and in project areas than collocated dyads, $\chi^{2}(4, N=1,902)=27.58, p<.001$, Cramer's $V=.12$. Collocated dyads also shared knowledge about shared problems relatively more often, while dyads from different rooms more often shared knowledge to help the other one with their problem, $\chi^{2}(2, N=1,899)=64.61, p<.001$, Cramer's $V=.17$; Figure 4 . Overall, H1 ("Dyads sharing a room [collocation], show different KS behavior than the other dyads") was confirmed, although the significant relationships had small effect sizes (considering the low Cramer's $V$ values).

The inter-visibility inside the room showed few differences in behavior. Although dyads sharing a room but not sitting within sight shared relatively more often at the coffee machine, $\chi^{2}(4, N=1,412)=80.84, p<.001$, Cramer's $V=.24$, three cells had an expected value lower than 5 . This is caused by the 


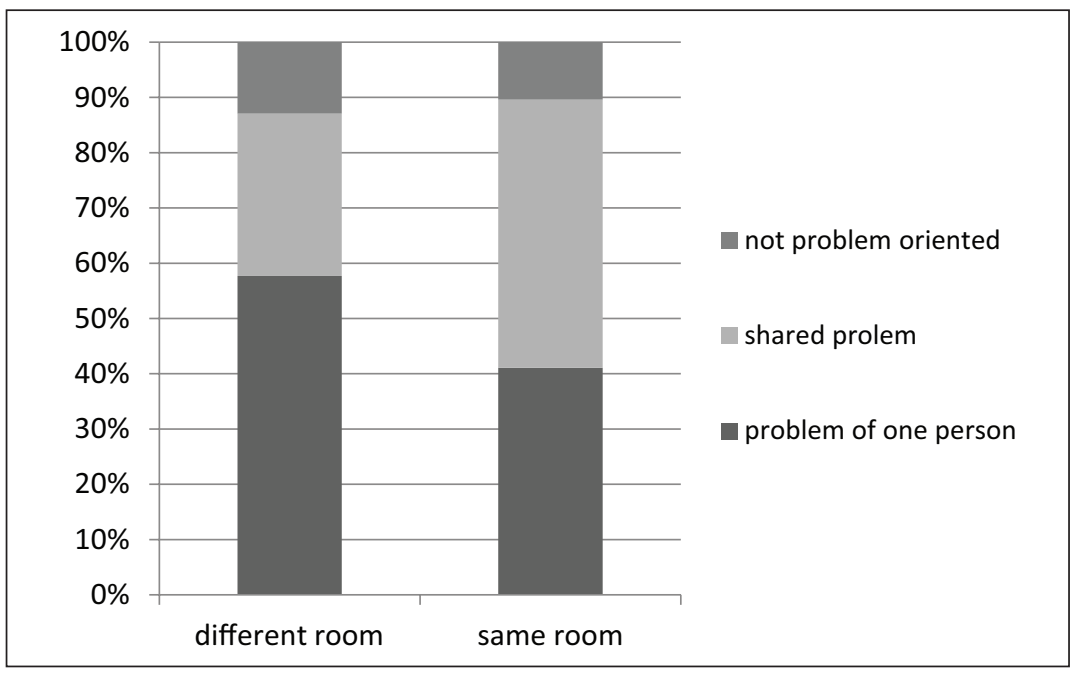

Figure 4. Differences in issues addressed in terms of occupying the same room or not.

small number of dyads that were unable to see each other and the general tendency to have most meetings at the workspace. So H2 ("Dyads that can see each other's workspaces [inter-visibility] show different KS behavior than the other dyads") was rejected.

For dyads that could hear one another (sitting within $7 \mathrm{~m}$ ), not all differences in behavior were significant. However, dyads sharing a room, but sitting outside hearing distance asked significantly more questions and gave relatively fewer descriptions although the effect size was small, $\chi^{2}(4, N=$ $2,578)=29.84, p<.001$, Cramer's $V=.11$; Figure 5. Also, dyads outside hearing distance more often shared knowledge at the coffee machine, $\chi^{2}(4, N$ $=1,412)=17.07, p=.002$, Cramer's $V=.11$. The tests on hearing distance for differences in intentionality or issues addressed (whose problem it was) were not significant. H3 ("Dyads sitting within hearing distance [overhearing] show different KS behavior than the other dyads") was accepted based on the significant differences for KS activities and locations, but the effect size again was not very strong.

The position in the building also revealed some differences in behavior, especially with regard to the location of KS meetings. Dyads not sharing a room, but sitting within proximity $(30 \mathrm{~m})$, shared significantly more knowledge at the workspace, with a medium effect size, $\chi^{2}(4, N=490)=41.50, p<$ .001 , Cramer's $V=.29$. Dyads at longer walking distances shared knowledge 


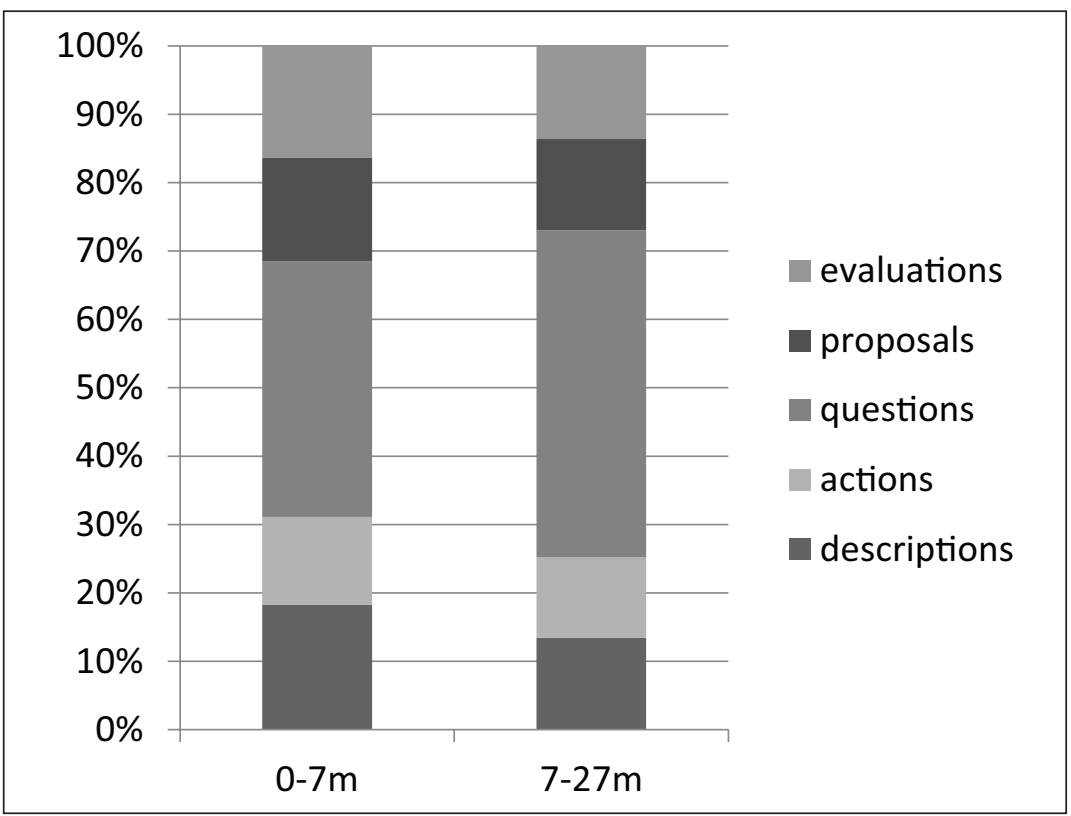

Figure 5. Differences in KS activities in terms of hearing distance.

Note. $\mathrm{KS}=$ knowledge sharing.

relatively more often in project rooms/laboratories and hallways and less at the workspace (Figure 6). Also, the intentionality of meetings was significantly different, $\chi^{2}(1, N=485)=11.87, p<.001$, Cramer's $V=.16$. Calculating the odds ratio showed that dyads within proximity were two times more likely to have intentional unscheduled visits than those at distances over 30 m. So H4 ("Dyads with a lower walking distance between their workspaces [proximity] show different KS behavior than the other dyads") was accepted.

Given that only $16 \mathrm{KS}$ meetings took place between dyads not working on the same floor, this created too many cells with values lower than 5 thus rendering $\chi^{2}$ tests unreliable. The tests of issues addressed and intentionality showed small, but significant relationships. Dyads from different floors shared less knowledge on shared problems, $\chi^{2}(2, N=1,899)=6.28, p=.043$, Cramer's $V=.06$, and their KS was less intentional, $\chi^{2}(1, N=1,891)=6.35$, $p=.013$, Cramer's $V=.06$. Nonetheless H5 ("Dyads with a workspace on the same floor show different KS behavior than the other dyads") was rejected, because of the small effect sizes and the very small number of meetings between dyads from different floors. 


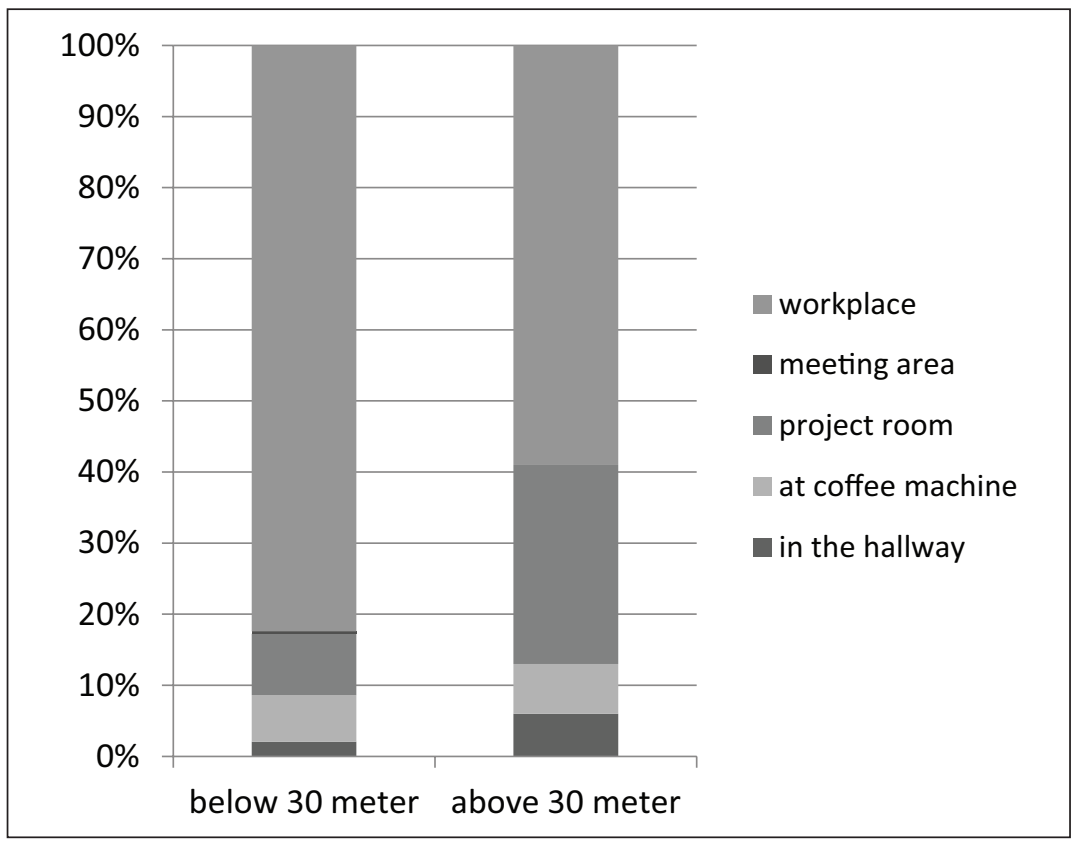

Figure 6. Differences in KS locations in terms of walking distance. Note. $\mathrm{KS}=$ knowledge sharing.

\section{Discussion and Conclusion}

The aim of this study was determining the relevance of very local layout metrics with respect to their impacts on specific behaviors during KS meetings. The data gathered about KS behavior from diaries of 138 employees and their spatial relationship with each participating colleague showed that the behavior is particularly different at this very local level within the building. Dyads sharing a room (H1) and particularly the ones with the ability to overhear each other (H3) shared knowledge through different KS activities, confirming both these hypotheses. The close proximity appears to be related to an awareness of each other, which prompted people to give descriptions if this seemed helpful, and to propose solutions and evaluations together. Dyads at greater distances apart had to ask questions on things that might otherwise have been made clear by overhearing/awareness. Berends (2003), who distinguished the five different ways of sharing knowledge used in this study, showed that making proposals and evaluating in particular lead to creation of new knowledge, while the other activities are mainly used to transfer existing 
knowledge. As new knowledge is vital for creativity and innovation (Nonaka, Toyama, \& Konno, 2000), these findings should stimulate innovative organizations to more carefully consider which employees to assign adjacent workspaces in larger rooms. One could think of specific project members that need to be more aware of each other during certain project phases or employees from different departments who have not worked together well enough in the past. Also, the increasing number of organizations with flexible seating in the office will have to consider whether they should develop some kind of workplace-use-policy to stimulate certain employees to collocate.

These findings add to previous studies, that measuring co-presence simply through sharing an open space/room (for dyads) or the number of colleagues in your room (for individuals) does not catch the entire mechanism of layout design. Although collocation matters and could be measured by simply counting the number of people in a room, overhearing further defines behavior and further increases the mean frequency of KS meetings (Table 2). Therefore, by looking specifically at the behavior of dyads, this study provided a closer look at creating awareness of each other in buildings. These new findings partly counter the tendency for organizations nowadays to create larger open areas with many workspaces to increase KS based on existing studies. They imply that especially the dyads in close collocation (overhearing in addition to mere inter-visibility at a larger distance) could have created previous findings of increased KS in large open areas. As overhearing fades outside 5 to $10 \mathrm{~m}$, open areas beyond 8 to 10 workspaces might not meet expectations of increased KS sufficiently. They could possible even create an opposite effect through excessive awareness of others, leading up to concentration loss.

Adding a certain limit of effective room sizes to existing theory is further supported by the finding that the relative number of coincidental meetings versus intentional visits to share knowledge was not significantly different for dyads sharing a room as for dyads from separate rooms, $\chi^{2}(2, N=1,891)$ $=0.54, p=.25$. Thus, existing theory that people collocated in the same room probably share more knowledge because they bump into each other coincidentally more often is also not supported. Collocated employees just as often intentionally look for a specific roommate with whom to share knowledge and did not benefit from increased coincidental encounters. This finding suggests that although interaction frequency has been shown to increase when people are roommates (Markhede \& Koch, 2007; Sailer et al., 2007), this increase might only relate to not-work-related talks. In light of the known downfalls of open layouts distracting employees through noise, such an increase might not be so desirable as assumed in such studies. Also, in practice, open layouts are popular to increase communication, where decreased 
concentration is seen as a "collateral damage" that is mitigated by providing concentration rooms. Without knowing whether the rise in communication actually increases organizational (innovation) outcome, the decision to design such open work environments might be taken too lightly sometimes.

For those dyads that cannot share a room, proximity $(<30 \mathrm{~m}$ walking distance) was still associated with differences in behavior, which confirmed existing research as expected. The more detailed measurement of behavior showed that dyads in this group might not differ in the KS activities that they used, but they did more often intentionally walk over to each other. It would be interesting to know if the existing need for $\mathrm{KS}$ of dyads at larger distances at that time was fulfilled otherwise (via email/phone call) or left unfulfilled. But even then, the sharing of tacit knowledge would have been harder as this is best when supported by motions and gestures in face-to-face meetings (Coradi et al., 2015). As sharing tacit knowledge specifically increases innovation quality (Wang \& Wang, 2012), this decreased intentionality of visits could hurt the innovation process. Organizations could try to promote walking over to colleagues at larger distances, to spread tacit knowledge further into the building.

Details on the locations where knowledge was shared showed that in general the collocated dyads used meeting areas for unplanned meetings. This suggests that they moved to a meeting area if the workspace was too disturbing or unsuitable for the unplanned meeting. But although meeting areas thus appear to support dyads when they want to have a meeting, it remains unclear how a possible effect can be optimized by design of these places. The other locations (hallways, coffee machines) were mainly used to share knowledge by dyads whose workspaces were at larger distances. But in general there were very few work-related meetings at these locations, so this might contribute little to the innovation process.

$\mathrm{H} 2$ (inter-visibility) and H5 (same floor) were rejected, as the specific behavior of the participants made it impossible to perform proper statistical tests (e.g., little variation in a variable). The effect sizes of the three accepted hypotheses varied from .06 to .29 , which are at best considered to be moderately strong. However, other quantitative studies on correlations of spatial layout with frequency of communication have also found low values (e.g., Toker \& Gray, 2008, with $r$-values between .30 and .54; Wineman \& Adhya, 2007, with $r$-values between .12 and .17). The correlations of these types of analyses cannot be expected to be as high as one finds in positivistic experiments trying to explain the exact effect of one metric on another. As Kabo et al. (2015) put it, "Spatial effects are probabilistic and contingent rather than deterministic and universal" (p. 59). Spatial design is a supportive resource and it cannot be expected to be responsible on its own for a high 
variance in KS behavior. But the significant differences have shown that CRE managers and the planners, designers, and others who work with them can support and improve the primary process of their client organization, which is after all their main task. A recent study (Gibler \& Lindholm, 2012) showed that until now, CRE managers trying to align with corporate innovation strategies are focusing more on technology support than on workspace design. The findings here provide them with broader possibilities to make a difference. The spatial variables can be taken up in the instructions, and later used to compare alternatives, using the actual layout drawings from an architect. As Sailer et al. (2007) stated, this detailed knowledge may provide architects the opportunity to design solutions that better match with the clients' needs, and provides CRE managers with solid and comprehensible evidence to back up their budget discussions with general management. This is true not only at the beginning of the design phase for new buildings but also during later postoccupancy evaluations that might lead to new interventions. The findings could also help office building managers in attracting and retaining tenants, by providing them with a more supportive office to rent when they do not want to own their real estate.

\section{Limitations and Recommendations}

A limitation of this study is that it was performed with only the research and development personnel of one production-focused organization. It needs to be repeated in more similar types of organizations to find out if the results are generalizable or perhaps industry-specific, and with other types of employees to find out if behavior during cross-functional KS meetings is similar. As service organizations also need to innovate (Adegoke, 2007), further research is needed to find out whether their employees show similar behavior and thus would need a similar or different spatial environment.

Further research on inter-visibility and its relationship with KS behavior is necessary, especially as open layouts are increasingly popular in both offices and research buildings. As Hua et al. (2011) showed, a vast open floor plan with high visibility does not necessarily increase the perception of support for collaboration among the employees themselves. Although open offices increase the frequency of interactions, the effect of visibility on more detailed KS behaviors remains unclear. Besides that, more research is necessary on the disadvantages of open layouts for organizational innovation. As Berends et al. (2011) stated, unrestrained KS can create cognitive overload for individuals. For innovation to take place, effective collaboration needs both KS and the possibility to focus (Heerwagen et al., 2004; Hua et al., 2011). Coradi et al. (2015) showed that workspace design became more important as an 
enabler when individuals required more balance between both activities. Koch and Steen (2012) added the need to distinguish the effect of interruptions on focused work on long and short questions. The activity/tasks might determine which spatial variables are best suited to improve support of KS behavior. And also the stage of these activities within the research and development process could require different spatial solutions (Coradi et al., 2015). Besides the tasks and ability to focus, innovation also needs individual-level creativity. Creative thought processes are influenced by the physical environment as well (Dul \& Ceylan, 2006; Martens, 2011; Van de Sande, 2012). More holistic as well as more detailed research on this would provide additional knowledge on KS behavior in spatial settings.

The size of the shared rooms was not taken up in the analyses, but $\mathrm{H} 3$ on overhearing showed that distance in a room does relate to actual KS behavior. As most of the participants were located in larger open areas, the findings are valid for large open areas but do not provide much insight yet in KS behavior in very small rooms. This needs further research. Other methods of measuring behavior (e.g., observation, activity tracking) could provide even more detail on KS behavior. With regard to measuring space, this study was just one of the few attempts to more accurately capture the spatial relationship between dyads. Researchers are currently constructing and testing many new spatial variables (like zone overlap; see Kabo et al., 2015) and other relevant influences (like water coolers as attractors; see Sailer, 2007). Further research comparing and testing such spatial variables in different building typologies will have to demonstrate which variables better predict collaborative behavior. When such variables are not so complicated as to be applicable to practice, they would provide CRE managers with a powerful tool to add strategic value for their clients and the end users of the buildings they manage.

\section{Declaration of Conflicting Interests}

The author(s) declared no potential conflicts of interest with respect to the research, authorship, and/or publication of this article.

\section{Funding}

The author(s) received no financial support for the research, authorship, and/or publication of this article.

\section{Note}

1. See, for example, results of an early phase (Appel-Meulenbroek, 2010), where space syntax-related isovist measures (e.g., compactness, occlusivity) were correlated with individual behavior. 


\section{References}

Adegoke, O. (2007). Innovation types and innovation management practices in service companies. International Journal of Operations \& Production Management, 27, 564-587.

Allen, T. J. (1977). Managing the flow of technology. Cambridge, MA: MIT Press.

Allen, T. J., \& Fustfeld, A. R. (1975). Research laboratory architecture and the structuring of communications. $R \& D$ Management, 5, 153-164. doi:10.1111/j.1467-9310.1975.tb01230.x

Allen, T. J., \& Henn, G. W. (2007). The organization and architecture of innovation: Managing the flow of technology. Burlington, MA: Butterworth-Heinemann.

Appel-Meulenbroek, H. A. J. A. (2010). Knowledge sharing through co-presence. Facilities, 28, 189-205. doi:10.1108/02632771011023140

Becker, F., \& Sims, W. (2001). Offices that work: Balancing communication, flexibility and cost. Ithaca, NY: International Workplace Studies Program, Cornell University.

Bell, S. M., \& Anderson, M. (1998). Workplace solutions. Journal of Corporate Real Estate, 1, 349-360. doi:10.1108/14630019910811132

Benedikt, M.L. (1979). To take hold of space: Isovists and isovist fields. Environment and Planning B, 6, 47-65. doi: 10.1068/b060047

Berends, H. (2005). Exploring knowledge sharing: Moves, problem solving and justification. Knowledge Management Research \& Practice, 3, 97-105. doi:10.1057/ palgrave.kmrp. 8500056

Berends, H., Garud, R., Debackere, K., \& Weggeman, M. (2011). Thinking along: A process for tapping into knowledge across boundaries. International Journal of Technology Management, 53, 69-88. doi:10.1504/IJTM.2011.037238

Berends, J. J. (2003). Knowledge sharing in industrial research (Doctoral dissertation). Eindhoven University of Technology, The Netherlands.

Blakstad, S. H., Hatling, M., \& Bygdås, A. L. (2009). The knowledge workplace: Searching for data on use of open plan offices. In Proceedings EFMC 2009 research symposium (pp. 1-14). Amsterdam, The Netherlands: Euroforum.

Bolger, N., Davis, A., \& Rafaeli, E. (2003). Diary methods: Capturing life as it is lived. Annual Review of Psychology, 54, 579-616. doi:10.1146/annurev. psych.54.101601.145030

Boutellier, R., Ullman, F., Schreiber, J., \& Nael, R. (2008). Impact of office layout on communication in a science-driven business. Research \& Development Management, 38, 372-391. doi:10.1111/j.1467-9310.2008.00524.x

Brown, M. G. (2008). Proximity and collaboration: Measuring workplace configuration. Journal of Corporate Real Estate, 10, 5-26.

Collins, A., Brown, J. S., \& Newman, S. (1989). Cognitive apprenticeship: Teaching the craft of reading, writing and mathematics. In L. Resnick (Ed.), Knowing, learning and instruction: Essays in honor of Robert Glaser (pp. 453-494). Hillsdale, NJ: Lawrence Erlbaum.

Coradi, A., Heinzen, M., \& Boutellier, R. (2015). A longitudinal study of workspace design for knowledge exploration and exploitation in the research and develop- 
ment process. Creativity and Innovation Management, 24, 55-71. doi:10.1111/ caim. 12099

Covi, L. M., Olson, J. S., \& Rocco, E. (1998). A room of your own: What do we learn about support of teamwork from assessing teams in dedicated project rooms? In N. Streitz, S. Konomi, \& H. J. Burkhardt (Eds.), Cooperative buildings (pp. 5365). Amsterdam, The Netherlands: Springer-Verlag.

Criscuolo, P., Salter, A., \& Ter Wal, A. (2010). The role of proximity in shaping knowledge sharing in professional services firms. In Opening up innovation: Strategy, organization and technology (pp. 1-27). London, England: Imperial College Business School.

Dul, J., \& Ceylan, C. (2006). Enhancing organizational creativity from an ergonomics perspective: The Creativity Development model. In E. Koningsveld (Ed.), Proceedings of the 16th world congress of the International Ergonomics Association (pp. 667-672). Maastricht, the Netherlands: Elsevier Science Inc.

Franz, G., Von der Heyde, M., \& Bülthoff, H. H. (2005). Predicting experiential qualities of architecture by its spatial properties. In B. Martens \& A. G. Keul (Eds.), Designing social innovation: planning, building, evaluating, proceedings IAPS 18 (pp. 157-166), Michigan, USA: Hogrefe \& Huber publishers.

Franz, G., \& Wiener, J. M. (2008). From space syntax to space semantics: A behaviorally and perceptually oriented methodology for the efficient description of the geometry and topology of environments. Environment and Planning B, 35, 574592. doi:10.1068/b33050

Gibler, K. M., \& Lindholm, A.-L. (2012). A test of corporate real estate strategies and operating decisions in support of core business strategies. Journal of Property Research, 29, 25-48. doi:10.1080/09599916.2011.608470

Goleman, D., \& Boyatzis, R. (2008, September). Social intelligence and the biology of leadership. Harvard Business Review, pp. 1-9.

Grajewski, T. R. (1992). Spatial configurations and interaction patterns within office buildings (Master thesis). University College London, England.

Greenberg, B. S., Eastin, M. S., Skalski, P., Cooper, L., Levy, M., \& Lachlan, K. (2005). Comparing survey and diary measures of Internet and traditional media use. Communication Reports, 18, 1-8. doi:10.1080/08934210500084164

Heerwagen, J. H., Kampschroer, K., Powell, K. M., \& Loftness, V. (2004). Collaborative knowledge work environments. Building Research \& Information, 32, 510-528. doi:10.1080/09613210412331313025

Hoegl, M., \& Proserpio, L. (2004). Team member proximity and teamwork in innovative projects. Research Policy, 33, 1153-1165. doi:10.1016/j. respol.2004.06.005

Hua, Y., Loftness, V., Heerwagen, J. H., \& Powell, K. M. (2011). Relationship between workplace spatial settings and occupant-perceived support for collaboration. Environment and Behavior, 43, 807-826. doi:10.1177/0013916510364465

Hua, Y., Loftness, V., Kraut, R., \& Powell, K. M. (2010). Workplace collaborative space layout typology and occupant perception of collaboration environment. Environment and Planning B, 37, 429-448. doi:10.1068/b35011 
Jassawalla, A. R., \& Sashittal, H. C. (1998). An examination of collaboration in high-technology new product development processes. The Journal of Product Innovation Management, 15, 237-254. doi:10.1016/S0737-6782(97)00080-5

Kabo, F., Hwang, Y., Levenstein, M., \& Owen-Smith, J. (2015). Shared paths to the lab: A sociospatial network analysis of collaboration. Environment and Behavior, 47, 57-84. doi:10.1177/0013916513493909

Kahn, K. B. (1996). Interdepartmental integration: A definition with implications for product development performance. The Journal of Product Innovation Management, 13, 137-151. doi:10.1016/0737-6782(95)00110-7

Kahn, K. B., \& McDonough, E. F. I. (1997). An empirical study of the relationships among co-location, integration, performance, and satisfaction. The Journal of Product Innovation Management, 14, 161-178. doi:10.1016/S07376782(97)00006-4

Keränen, J., Virjonen, P., \& Hongisto, V. (2008). Characterization of acoustics in open offices: Four case studies. In Proceedings of the international congress on acoustics (pp. 549-554). Paris, France: DC/ConfOrg.

Koch, D., \& Steen, J. (2012). Decomposing programmes: Re-coding hospital work with spatially syntactic information. In M. Greene, J. Reyes, \& A. Castro (Eds.), 8th space syntax symposium (pp. 8145:1-20). Santiago de Chile, Chile: PUC.

Markhede, H., \& Koch, D. (2007). Positioning analysis: Social structures in configurative modelling. In A. S. Kubat, O. Ertekin, Y. I. Güney, \& E. Eyüboglu (Eds.), 6th space syntax symposium (pp. 069:1-9). Istanbul, Turkey: ITU Faculty of architecture.

Martens, Y. (2011). Creative workplace: Instrumental and symbolic support for creativity. Facilities, 29, 63-79. doi:10.1108/02632771111101331

Nenonen, S. (2005). The nature of the workplace for knowledge creation (Doctoral dissertation). Helsinki University of Technology, Finland.

Nonaka, I., \& Konno, N. (1998). The concept of "Ba": Building a foundation for knowledge creation. California Management Review, 40(3), 40-54. doi: $10.2307 / 41165942$

Nonaka, I., \& Takeuchi, H. (1995). The knowledge-creating company: How Japanese companies create the dynamics of innovation. Oxford, UK: Oxford University Press.

Nonaka, I., Toyama, R, \& Konno, N. (2000). SECI, ba and leadership: A unified model of dynamic knowledge creation. Longe Range Planning, 33(1), 5-34. doi: 10.1016/S0024-6301(99)00115-6

Peponis, J., Bafna, S., Bajaj, R., Bromberg, J., Congdon, C., Rashid, M., . . Zimring, C. (2007). Designing space to support knowledge work. Environment and Behavior, 39, 815-840. doi:10.1177/0013916506297216

Polanyi, M. (1966). The tacit dimension. London, UK: Routledge \& Kegan Paul.

Rashid, M., Kampschroer, K., Wineman, J., \& Zimring, C. (2006). Spatial layout and face-to-face interaction in offices: A study of the mechanisms of spatial effects on face-to-face interaction. Environment and Planning B, 33, 825-844. doi: $10.1068 / \mathrm{b} 31123$ 
Rashid, M., Zimring, C., Wineman, J., Flanigam, T., Nubani, L., \& Hammash, R. (2005). The effects of spatial behaviours and layout attributes on individual's perception of psychosocial constructs in offices. In A. van Nes (Ed.), 5th space syntax symposium (pp. 71-88). Delft, The Netherlands: Techne Press.

Sailer, K. (2007). Movement in workplace environments: Configurational or programmed? In A. S. Kubat, Ö. Ertekin, Y. I. Güney, \& E. Eyüboglu (Eds.), 6th space syntax symposium (pp. 1-14). Istanbul, Turkey: ITÜ Faculty of Architecture.

Sailer, K., Budgen, A., Lonsdale, N., Turner, A., \& Penn, A. (2007). Effective workplaces: Bridging the gap between architectural research and design practice. In A. S. Kubat, O. Ertekin, Y. I. Güney, \& E. Eyüboglu (Eds.), 6th space syntax symposium (pp. 1-6). Istanbul, Turkey: ITU Faculty of architecture.

Sailer, K., \& McCulloh, I. (2012). Social networks and spatial configuration: How office layouts drive social interaction. Social Networks, 34, 47-58. doi:10.1016/j. socnet.2011.05.005

Sailer, K., \& Penn, A. (2009). Spatiality and transpatiality in workplace environments. In D. Koch, L. Marcus, \& J. Steen (Eds.), 7th space syntax symposium (pp. 1-11). Stockholm, Sweden: TRITA-ARK- Forskningspublikation.

Serrato, M., \& Wineman, J. (1999). In F. Holanda (Ed.), 2nd space syntax symposium (pp. 11.1-11.8). Brasilia, Brazil: University of Brasilia.

Shpuza, E. (2006). Floorplate shapes and office layouts: A model of the effect of floorplate shape on circulation integration (Doctoral dissertation). Georgia Institute of Technology, USA.

Song, M., Berends, H., Van der Bij, H., \& Weggeman, M. (2007). The effect of IT and co-location on knowledge dissemination. The Journal of Product Innovation Management, 24, 52-68. doi:10.1111/j.1540-5885.2006.00232.x

Spiliopoulou, G., \& Penn, A. (1999). Organisations as multi-layered networks: Face to face, email and telephone interaction in the workplace. In F. Holanda (Ed.), 2nd space syntax symposium (pp. A1.1-A1.24). Brasilia, Brazil: University of Brasilia.

Steeneken, H. J. M. (1998). Personal active noise reduction with integrated speech communication devices: Development and assessment. Noise \& Health, 1, 64-75.

Tan, A. A. W. (2003). The reliability and validity of interactive virtual reality computer experiments (Doctoral dissertation). Eindhoven University of Technology, The Netherlands.

Thompson, B. (2008). Computing and interpreting effect sizes, confidence intervals, and confidence intervals for effect sizes. In J. W. Osborne (Ed.), Best practices in quantitative methods (pp. 246-262). Thousand Oaks, CA: Sage.

Toker, U., \& Gray, D. O. (2008). Innovation spaces: Workspace planning and innovation in U.S. university research centers. Research Policy, 37, 309-329. doi:10.1016/j.respol.2007.09.006

Turner, A. (2001). Depthmap: A program to perform visibility graph analysis. In J. Peponis, J. Wineman, \& S. Bafna (Eds.), 3rd space syntax symposium (pp. 31.131.9). Atlanta, GA: Georgia Tech. 
Turner, A., Doxa, M., O’Sullivan, D., \& Penn, A. (2001). From isovists to visibility graphs: A methodology for the analysis of architectural space. Environment and Planning B, 28, 103-121. doi:10.1068/b2684

Van, de, \& Sande, L. (2012). Creativity and place: Does where you are impact on how or what you think? Work \& Place, 1, 14-17.

Wang, Z., \& Wang, N. (2012). Knowledge sharing, innovation and firm performance. Expert Systems With Applications, 39, 8899-8908.

Ward, V., \& Holtham, C. (2000). The role of private and public spaces in knowledge management. In Proceedings of the Knowledge management conference. Coventry, UK: University of Warwick.

Wenmaekers, R. H. C., Van Hout, N. H. A. M., Hak, C. C. J. M., \& Van Luxemburg, R. C. J. (2009). The effect of room acoustics on the measured speech privacy in two typical European open plan offices. In J. S. Bolton, B. Gover, \& C. Burroughs (Eds.), Proceedings Inter-noise, 2009 (pp. 74-79). Ottawa, Canada: Curran Associates, Inc.

Wineman, J. D., \& Adhya, A. (2007). Enhancing workspace performance: Predicting the influence of spatial and psychosocial factors on job satisfaction. In D. Koch, L. Marcus, \& J. Steen (Eds.), 7th space syntax symposium (pp. 1-16). Stockholm, Sweden: TRITA-ARK- Forskningspublikation.

Wineman, J. D., Kabo, F. W., \& Davis, G. F. (2009). Spatial and social networks in organizational innovation. Environment and Behavior, 41, 427-442. doi:10.1177/0013916508314854

Wineman, J. D., Hwang, Y., Kabo, F., Owen-Smith, J., \& Davis, G. F. (2014). Spatial layout, social structure, and innovation in organizations. Environment and Planning B, 41, 1100-1112. doi:10.1068/b130074p

\section{Author Biographies}

Rianne Appel-Meulenbroek is an assistant professor in corporate real estate management and workplace. Her research focuses on the way building design can support an organization through productivity of employees, innovation, knowledge sharing, and so forth and how this is best managed.

Bauke de Vries is a professor in design systems. His group focuses on simulation of human behavior in the built environment, multi-agent systems for design and planning, and geo-data and building information modeling (BIM) for the support of collaborative design.

Mathieu Weggeman is a professor of organization science. His primary expertise lies in the field of organizational design, innovation management, and work processes in knowledge-intensive organizations. 